\title{
Impaired myocardial capillarogenesis and increased adaptive capillary growth in FGF2-deficient mice
}

\author{
Kerstin Amann ${ }^{1}$, Jörg Faulhaber ${ }^{2}$, Valentina Campean ${ }^{1}$, Vitali Balajew ${ }^{3}$, Rosanna Dono ${ }^{4}$, \\ Gerhard Mall ${ }^{5}$ and Heimo Ehmke ${ }^{2}$ \\ ${ }^{1}$ Department of Pathology, University of Erlangen-Nürnberg, Erlangen, Germany; ${ }^{2}$ Institut for Vegetative \\ Physiology und Pathophysiology, University of Hamburg, Hamburg, Germany; ${ }^{3}$ University of Heidelberg, \\ Heidelberg, Germany; ${ }^{4}$ INSERM UMR 623, IBDM, Marseille Cedex, France and ${ }^{5}$ Department of Pathology, \\ Darmstadt, Germany
}

\begin{abstract}
Basic fibroblast growth factor (FGF2) plays a major role in angiogenesis and capillary growth. In contrast to vascular endothelial growth factor, which is required for proliferation and survival of endothelial cells, FGF2 does not seem to be essential since the Fgf2 knockout is not lethal. Therefore, the precise genetic and physiological roles of FGF2 for capillary development and adaptation remain to be determined. Here we show that myocardial capillary supply is normal at birth, but significantly reduced by $\sim 25 \%$ in adult $\mathrm{Fgf2}^{+/-}$and Fgf $^{-1-}$ mice as compared with wild-type littermates. In contrast, after induction of myocardial hypertrophy by continuous infusion of angiotensin II (ANG II) for 6 days marked capillary growth was seen in both $\mathrm{Fgf2}^{+/-}$and Fgf2 ${ }^{-1}$ mice, but not in wild-type littermates. These data demonstrate that two intact Fgf2 genes are necessary for normal capillary development after birth, whereas FGF2 seems to be dispensable for adaptive myocardial capillary growth in the adult mouse.
\end{abstract}

Laboratory Investigation (2006) 86, 45-53. doi:10.1038/labinvest.3700359; published online 24 October 2005

Keywords: FGF2; heart; capillaries; ANG II; myocardial hypertrophy

Basic fibroblast growth factor (FGF2) belongs to the family of heparin binding growth factors (FGFs) which are widely distributed in richly vascularized tissues (brain, kidney, retina, adrenal glands, heart, placenta). ${ }^{1,2}$ FGF2 exerts various physiological roles in vascular development ${ }^{3,4}$ and control of blood pressure..$^{5-7}$ It is also involved in cerebral cortex development and function,,$^{5,8,9}$ bone formation ${ }^{10}$ and cardiac growth. ${ }^{11}$

Together with acidic fibroblast growth factor (FGF1) and vascular endothelial growth factor (VEGF) FGF2 is involved in angiogenesis ${ }^{3,4,12,13}$ particularly during growth of collaterals in response to hypoxia and to myocardial ischemia. ${ }^{14-18}$ FGF2 is expressed in vascular smooth muscle cells, ${ }^{19}$ endothelial cells ${ }^{20}$ and postmitotic cardiomyocytes; ${ }^{21}$

Correspondence: Dr K Amann, MD, Department of Pathology, University of Erlangen-Nürnberg, Krankenhausstr. 8-10, Erlangen D-91054, Germany.

E-mail: Kerstin.Amann@patho.imed.uni-erlangen.de

Received 22 August 2003; revised 28 July 2005; accepted 23

August 2005; published online 24 October 2005 it stimulates proliferation of endothelial cells, vascular smooth muscle cells and fibroblasts. ${ }^{19-21}$ It is chemotactic for endothelial cells in vitro, thus inducing capillary tube formation and regulating blood vessel growth. ${ }^{20}$

FGF2 has been isolated from and localized in the heart. $^{21-23}$ Increased mechanical load to the heart leads to FGF2 release from cardiomyocytes, thus inducing adaptive myocardial growth. ${ }^{24}$ In vitro, FGF2 increased DNA synthesis and proliferation of neonatal rat cardiac myocytes indicating an important role for myocyte growth and differentiation. ${ }^{25}$

Although it is clear that FGF2 is involved in the capillary response to ischemia, it has not been determined whether FGF2 is necessary for capillarogenesis during physiological growth and/or for adaptive capillary growth during cardiac hypertrophy. In contrast to VEGF, which is required for proliferation and survival of endothelial cells, ${ }^{26-29}$ FGF2 does not seem to be essential since the Fgf2 knockout is not lethal. ${ }^{5,7-9}$

In the present study, two experimental strategies were used in order to investigate the role of 
FGF2 for normal capillary development and adaptation during cardiac hypertrophy. In a combined developmental and physiological approach myocardial capillary supply was analyzed using stereological techniques in adult heterozygous and homozygous FGF2-deficient mice and in wild-type littermates under baseline conditions and after 6 days of continuous angiotensin II (ANG II) infusion to induce myocardial hypertrophy. Specifically, we investigated (i) whether adult FGF2-deficient mice have a distinct cardiac phenotype at the microscopical level, that is, cardiac capillaries, arteries, and interstitial tissue, and (ii) whether capillary adaptation in response to myocardial hypertrophy is altered by a reduced formation of FGF2.

\section{Materials and methods}

\section{Generation of $\mathrm{Fgf2}^{+/-}$and $\mathrm{Fgf2}^{-/-}$}

Male and female $F g f 2^{-1-}$ mice were generated through gene targeting in R1-ES cells as described in detail previously. ${ }^{5}$ Briefly, mice of mixed C57BL/ $6 \mathrm{~J} \times 129 / \mathrm{Sv}$ background were generated as follows: chimeras (ES cells of 129/sv background) were crossed to C57BL/6J females and their heterozygous $(+/-)$ F1 progeny was crossed to generate all three genotypes. These mice and subsequent offspring were used for all studies. Genotyping was carried out in every animal either by PCR using specific oligonucleotides or by Southern blotting. FGF2 serum levels were decreased by $50 \%$ in $\mathrm{Fgf2}^{+/-}$ mice and they were zero in Fgf2 $2^{-1-}$ animals. ${ }^{5}$ The cardiovascular studies were performed in 4-5 months old sibling animals.

In a separate experiment myocardial capillarization was analyzed in newborn wild-type, $\mathrm{Fgf2}^{+/-}$, and $\mathrm{Fgf2}^{-/-}$mice on postnatal day 1 . All mice were regenotyped after the experiments using either PCR or Southern blotting.

\section{ANG II Infusion}

The effect of a continuous ANG II infusion $(2 \mathrm{ng} / \mathrm{g}$ body weight/min for 6 days, via osmotic minipump,
Alzet, model 1007 D) on myocardial growth and on capillary adaptation to myocardial hypertrophy was investigated in wild-type, $\mathrm{Fgf2} 2^{+/-}$and $\mathrm{Fgf} 2^{-/-}$mice ( $n=6-3$ animals per group). The dose of ANG II was adjusted to induce an increase in blood pressure of $20 \mathrm{mmHg}$ in normal mice as determined in pilot experiments and previous studies. ${ }^{5}$ On the day of recording, mice were instrumented with a carotid artery catheter during general anesthesia (fentanyl $0.03 \mu \mathrm{g} / \mathrm{g}$ body weight, fluanisone $10 \mu \mathrm{g} / \mathrm{g}$ body weight) and midazolam $10 \mu \mathrm{g} / \mathrm{g}$ body weight) and mean blood pressure and heart rate were measured in awake, resting mice (see Dono et $a l^{5}$ ). Infusion or overproduction of ANG II is known to induce myocardial hypertrophy by an increase in blood pressure and thus an increased myocardial work load as well as by direct growth stimulatory effects on cardiac myocytes, interstitial cells and vascular smooth muscle cells. ${ }^{30}$

\section{Cardiovascular Studies}

Implantation of carotid catheters (polyethylene catheter with outer diameter of $400 \mu \mathrm{m}$ ), measurement of mean intra-arterial blood pressure and heart rate were performed as described previously. ${ }^{5}$ All animal experiments were approved by the local authorities and performed according to the EMBL guidelines on animal experimentation (for animal numbers per group see Tables 1 and 2).

Table 1 Blood pressure, body weight, heart weight and left ventricular weight in untreated wild-type, Fgf2 $2^{+/-}$and $F g f 2^{-/}$ mice

\begin{tabular}{lcccc}
\hline Groups & $\begin{array}{c}\text { Mean arterial } \\
\text { blood } \\
\text { pressure } \\
(\mathrm{mmHg})\end{array}$ & $\begin{array}{c}\text { Body } \\
\text { weight } \\
\text { (g) }\end{array}$ & $\begin{array}{c}\text { Heart } \\
\text { weight } \\
\text { (mg) }\end{array}$ & $\begin{array}{c}\text { Left } \\
\text { ventricular } \\
\text { weight }(\mathrm{mg})\end{array}$ \\
\hline Wild-type $(n=10)$ & $124 \pm 4$ & $25.4 \pm 0.9$ & $133 \pm 6$ & $105 \pm 6$ \\
$F g f^{+-}(n=11)$ & $133 \pm 4$ & $26.2 \pm 0.5$ & $134 \pm 2$ & $105 \pm 2$ \\
$F g f^{--}(n=13)$ & $118 \pm 3$ & $26.8 \pm 0.8$ & $141 \pm 5$ & $110 \pm 6$ \\
ANOVA & NS & NS & NS & NS \\
\hline
\end{tabular}

NS $=$ not significant

Data are mean \pm s.e.m.

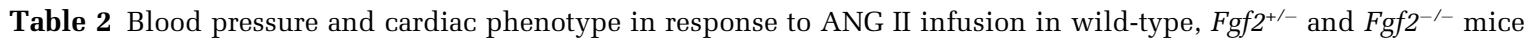

\begin{tabular}{|c|c|c|c|c|c|c|c|}
\hline Groups & $\begin{array}{l}\text { Mean } \\
\text { arterial } \\
\text { blood } \\
\text { pressure } \\
\text { (mmHg) }\end{array}$ & $\begin{array}{c}\text { Left } \\
\text { ventricular } \\
\text { weigh body } \\
\text { weight } \\
\text { (mg/g) }\end{array}$ & $\begin{array}{l}\text { Myocyte } \\
\text { diameter } \\
(\mu \mathrm{m})\end{array}$ & $\begin{array}{c}\text { Volume } \\
\text { density of } \\
\text { interstitial } \\
\text { tissue (\%) }\end{array}$ & $\begin{array}{c}\text { Length } \\
\text { density of } \\
\text { capillaries } \\
\left(\mathrm{mm} / \mathrm{mm}^{3}\right)\end{array}$ & $\begin{array}{l}\text { Wall thick- } \\
\text { ness of } \\
\text { arteries }(\mu \mathrm{m})\end{array}$ & $\begin{array}{c}\text { Wall-lumen } \\
\text { ratio of } \\
\text { arteries } \\
(\mu \mathrm{m} / \mu \mathrm{m})\end{array}$ \\
\hline Wild-type ANG II $(n=6)$ & $144 \pm 5$ & $4.85 \pm 0.04$ & $18.7 \pm 0.49$ & $3.48 \pm 0.86$ & $3521 \pm 290$ & $2.80 \pm 0.18$ & $0.09 \pm 0.004$ \\
\hline $\mathrm{Fgf2}^{+/-}$ANG II $(n=12)$ & $151 \pm 4$ & $5.49 \pm 0.26$ & $20.3 \pm 0.59$ & $4.47 \pm 0.64$ & $3373 \pm 289$ & $2.80 \pm 0.13$ & $0.11 \pm 0.009$ \\
\hline Fgf $^{-\prime-}$ ANG II $(n=13)$ & $146 \pm 4$ & $5.26 \pm 0.24$ & $19.8 \pm 0.23$ & $4.70 \pm 0.53$ & $3933 \pm 232$ & $3.62 \pm 0.33$ & $0.09 \pm 0.002$ \\
\hline ANOVA & NS & $\overline{N S}$ & $\overline{N S}$ & $\overline{N S}$ & NS & NS & NS \\
\hline
\end{tabular}

NS $=$ not significant.

Data are mean \pm s.e.m. 
Analysis of Myocardial Capillarization in Newborn Wild-Type, Fgf2 ${ }^{+/-}$and FGF2 ${ }^{-/-}$Mice

To investigate myocardial capillarization in newborn mice an immunohistochemical approach was used since perfusion fixation and orientator technique cannot be used in newborn mice. For capillary staining a CD34 rat polyclonal antibody (BD Pharmingen, concentration 1:50) was used. Pretreatment was performed using a pressure cooker for $5 \mathrm{~min}$ in preheated target retrieval solution pH 6.0 (Dako Cytomation, Denmark). The expression of CD34 was analyzed on paraffin sections by computer-aided planimetry in a blinded fashion, that is, the observer was unaware of the group the specimen belonged to. Three to five digital images of each sample $(n=10-$ 15 per group) were obtained and quantitatively analyzed by analySIS (Soft Imaging System $\mathrm{GmbH}$ ) using standardized settings. The mean number of CD34-positive capillary profiles were counted in the entire tissue sections and expressed as capillaries per $\mathrm{mm}^{2}$ tissue (magnification $\times 200$ ).

\section{Analysis of Myocardial Capillarization after ANG II Infusion}

At the end of the experiment, the abdominal aorta was catheterized under general anesthesia (see above). Then, retrograde vascular perfusion was performed at a controlled pressure as described in detail. ${ }^{31}$ First, 10\% dextran with procain hydrochloride was used for 2 min to relax the vasculature, then 3\% glutaraldehyde was used for $5 \mathrm{~min}$ as fixative. After the perfusion, the heart of each animal was taken out for determination of weight and volume. In all, 12 small pieces $\left(2 \times 2 \times 2 \mathrm{~mm}^{3}\right)$ of the left ventricle including the septum were sampled according to a modification of the orientator method, ${ }^{31,32}$ and embedded in Epon-Araldite. This technique was developed to determine the capillary number per area and to allow a simple estimation of capillary length density (by multiplying capillery density by 2) as a three-dimensional parameter of myocardial capillarization. ${ }^{31,32}$ It has been used for determination of myocardial capillary supply in several rat and mice models. Semithin sections $(0.8 \mu \mathrm{m})$ were cut and stained with methylene-blue/basic fuchsin and examined using light microscopy with oil immersion and phase contrast at a magnification of 1000:1. In several animals per group ultrathin sections were cut, stained with lead citrate and uranyl acetate and qualitatively investigated using a Zeiss EM 10 electron microscope (Zeiss Co., Oberkochen, Germany) at various magnifications.

\section{Quantitative Stereology}

All investigations were performed in a blinded manner, that is, the observer was unaware of the experimental protocol. Uniformly random sampling was achieved by preparing a set of equidistant slices of the left ventricle and the interventricular septum with a random start. Three slices of the left ventricle were selected by area-weighted sampling and processed according to the orientator method. ${ }^{31,32}$ Stereological analysis was performed on 12 random samples of differently orientated sections of the left ventricular myocardium including the inter ventricular septum.

In brief, the length density $\left(L_{V}\right)$ of capillaries, that is, the length of capillaries per unit tissue volume, a three-dimensional parameter of myocardial capillary supply, and the volume density $\left(V_{\mathrm{V}}\right)$ of cardiac nonvascular interstititum, that is, the volume of nonvascular interstitial cells and fibers per unit myocardial tissue volume (excluding endothelial cells), were measured in eight systematically subsampled areas per section using a Zeiss eyepiece with 100 points for point counting. In all, 12 orientator sections per animal (a total of 96 test areas per animal) were investigated resulting in a single mean value per heart. Volume density $\left(V_{\mathrm{V}}\right)$ was obtained according to the equation $P_{\mathrm{P}}=V_{\mathrm{V}}$ (with $P_{\mathrm{P}}$ is point density) and length density $\left(L_{\mathrm{V}}\right)$ was determined using the equation $L_{\mathrm{V}}=2 Q_{\mathrm{A}}$ (where $Q_{\mathrm{A}}$ is area density, ie the number of capillary transects per area of myocardial reference tissue). Reference volume was the total myocardial tissue exclusive of noncapillary vessels. Total length of capillaries per heart $\left(L_{\text {captot }}\right)$ was calculated using the formula: $L_{\text {captot }}=L_{\mathrm{V}} \times V$ with $V=\mathrm{m} / \delta$ and $\delta=1.04$ $\mathrm{g} / \mathrm{cm}^{3}$ (Törnig et $\mathrm{al}^{31}$ ). Intercapillary distance (ICD) was calculated according to a modification of the formula of Henquel and Honig ${ }^{33}$ as ICD $=\left(\sqrt{ }\left(4 \times Q_{\mathrm{A}} / \sqrt{ } 3\right)\right): 2$.

In our hands the method of capillary counting on semithin sections was superior to all other methods (ie immunohistochemical staining of capillaries using factor VIII or CD 31) if adequate perfusion fixation was used to open the capillaries. ${ }^{31,32}$ We had shown previously that counting of capillaries is very reliable and reproducible on semithin sections since plastic embedding does not lead to tissue shrinkage and capillaries can easily be identified and counted. ${ }^{31}$ In the present study, using electron microscopy on ultrathin sections we could exclude collapse of myocardial capillaries after perfusion fixation.

\section{Statistics}

Data are given as mean \pm standard error (s.e.m.). After testing for normality, one-way ANOVA or Kruskal-Wallis test, respectively, were used for analysis of variance. Significance between groups was assessed using Duncan's multiple range test. Results were considered significant when probability of error $(P)$ was less than 0.05 .

\section{Results}

Effect of Disruption of the Fgf2 Gene on Myocardial Architecture and Capillarization in Adult Mice

At the end of the experiment body weights were similar in all experimental groups as were absolute 
and relative heart weights and left ventricular weights in the three untreated groups (Table 1).

Mean arterial blood pressure tended to be lower in $\mathrm{Fgf2} 2^{-{ }^{-}}$than in $\mathrm{Fgf2} 2^{+/-}$mice and wild-type littermates. The difference, however, did not reach statistical significance. Also, there was no correlation of blood pressures with heart weights or left ventricular weights, which tended to be higher in Fgf2 ${ }^{-/-}$mice (Table 1).

Figure 1 shows that the number of capillary profiles per area myocardium is markedly lower in $\mathrm{Fgf2}^{+/-}$(Figure 1b) and Fgf2 $2^{-/-}$(Figure 1c) mice compared to wild-type animals (Figure 1a). Figure 2 indicates that three-dimensional myocardial capillary supply (assessed as capillary length density $\left(L_{V}\right)$, that is, capillary length per volume myocardium) was significantly lower in Fgf2 $2^{+-}\left(3228 \pm 245 \mathrm{~mm} / \mathrm{mm}^{3}\right)$ and $F g f 2^{-\prime-}$ mice $\left(3385 \pm 241 \mathrm{~mm} / \mathrm{mm}^{3}\right)$, respectively, than in $\mathrm{Fgf2}^{+/+}$littermates $\left(4403 \pm 290 \mathrm{~mm} / \mathrm{mm}^{3}\right.$, $P<0.05$, Figures 1 and 2). There were no differences in capillary length density between male and female animals of the same genotype.

Total capillary length per heart $\left(L_{\text {captot }}\right)$ was also significantly lower in $\mathrm{Fgf2}^{+/-}(3.23 \pm 0.22 \mathrm{~m})$ and $F_{g f 2^{-1}}(3.50 \pm 0.20 \mathrm{~m})$ mice than in wild-type controls $(4.57 \pm 0.38 \mathrm{~m}, P<0.05)$. In parallel with the decrease in capillary length density, mean ICD (ie the distance between the capillary and the center of the adjacent myocyte) increased. It was significantly higher in $\mathrm{Fgf2}^{+/-}(19.4 \pm 2.67 \mu \mathrm{m})$ and $\mathrm{Fgf2}^{-/}$ $(18.9 \pm 2.66 \mu \mathrm{m})$ than in wild-type animals $(16.0 \pm$ $2.65 \mu \mathrm{m}, P<0.05)$.

In contrast, mean myocyte diameter was not significantly different between wild-type mice $(17.1 \pm 0.33 \mu \mathrm{m})$ and FGF2-deficient mice (17.8 \pm $0.35 \mu \mathrm{m}$ in $\mathrm{Fgf2}^{+/-}$and $17.7 \pm 0.27 \mu \mathrm{m}$ in $\mathrm{Fgf2}^{-/-}$). The same was true for wall thickness and wall to lumen ratio of intramyocardial arteries and volume density of myocardial interstitial tissue $\left(V_{V_{\text {int }}}\right)$ $\left(\mathrm{Fgf2} 2^{+/+}: \quad 1.69 \pm 0.18 \%, \quad F g f 2^{+/-}: \quad 1.91 \pm 0.18 \%\right.$, Fgf2 ${ }^{-/-}: 2.50 \pm 0.23 \%, P>0.05$ ). The number of intramyocardial arteries per area myocardium was not different between the genotypes indicating a normal representation of arterioles in mice lacking FGF2 compared to wild-type controls.

The ultrastructure of myocytes and capillaries was studied by qualitative electron microscopy in several randomly chosen animals per group ( $n=2-4$ per group). The findings are illustrated in Figure 3a-c. Electron microscopical investigations showed no structural abnormalities of cardiomyocytes and capillaries in the heart of $\mathrm{Fgf2}^{+/-}$ (Figure 3b) or Fgf2 ${ }^{-/-}$(Figure 3c) mice compared to wild-type animals (Figure 3a).

In order to determine, whether the reduced myocardial capillarization observed in adult FGF2deficient mice results from an altered embryonic development, myocardial capillary supply was assessed in newborn mice by immunohistochemical staining of CD34 as the number of capillary profiles per area myocardium $\left(Q_{\mathrm{A}}\right)$. No significant differ-
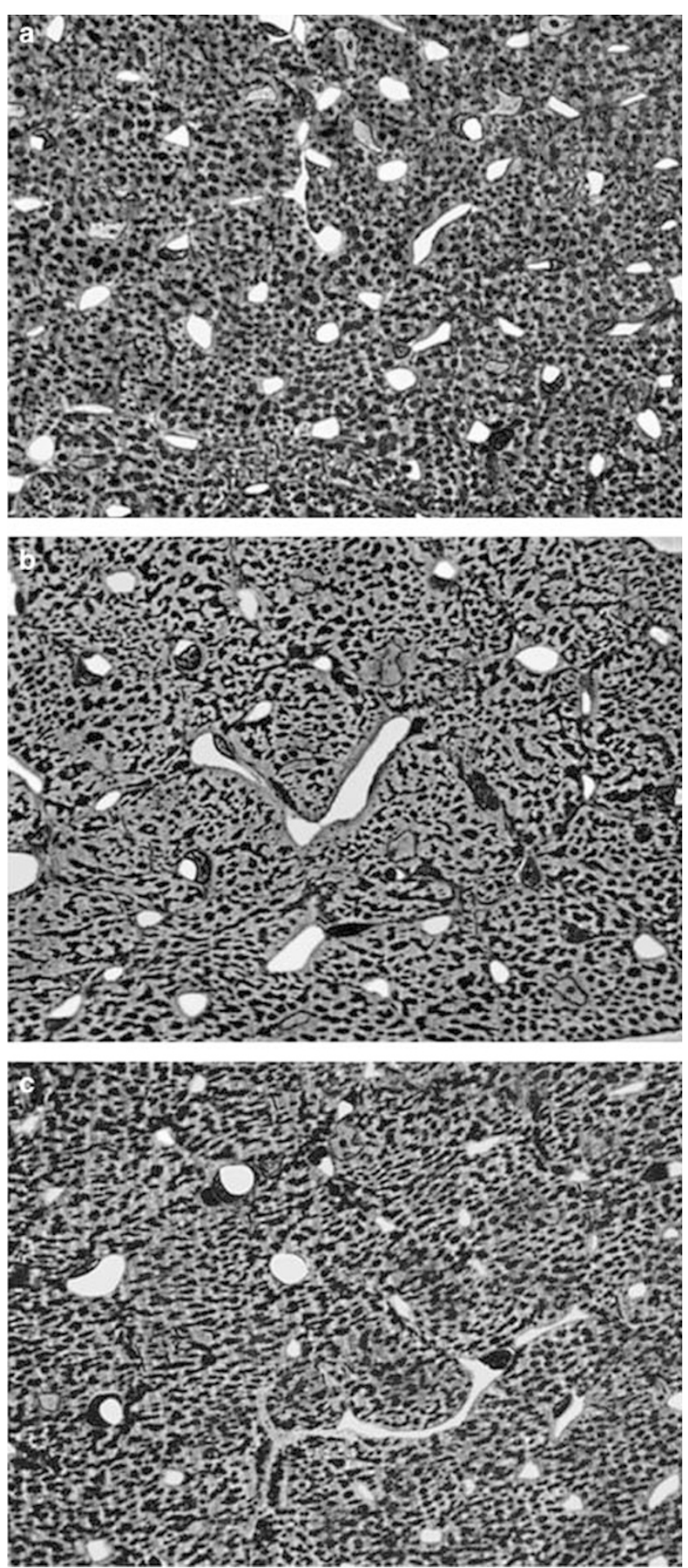

Figure 1 Reduced myocardial capillarization in $\mathrm{Fgf2}^{+/-}$and Fgf $2^{-1-}$ mice. (a-c) Light microscopical aspect of myocardial

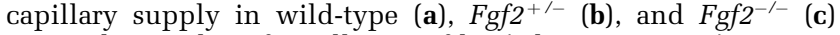
mice. The number of capillary profiles (white structures) per area myocardium is markedly lower in $\mathrm{Fgf2}^{+/-}$(b) and $\mathrm{Fgf2}^{-{ }^{-}}$(c) mice compared to wild-type mice (a). Semithin section, magnification: 1:500.

ences were observed between wild-type, $\mathrm{Fgf2} 2^{+/}$ and $F g f 2^{-1-}$ mice. The number of capillary profiles per area myocardium $\left(1 / \mathrm{mm}^{2}\right)$ was $1969 \pm 377$ in 


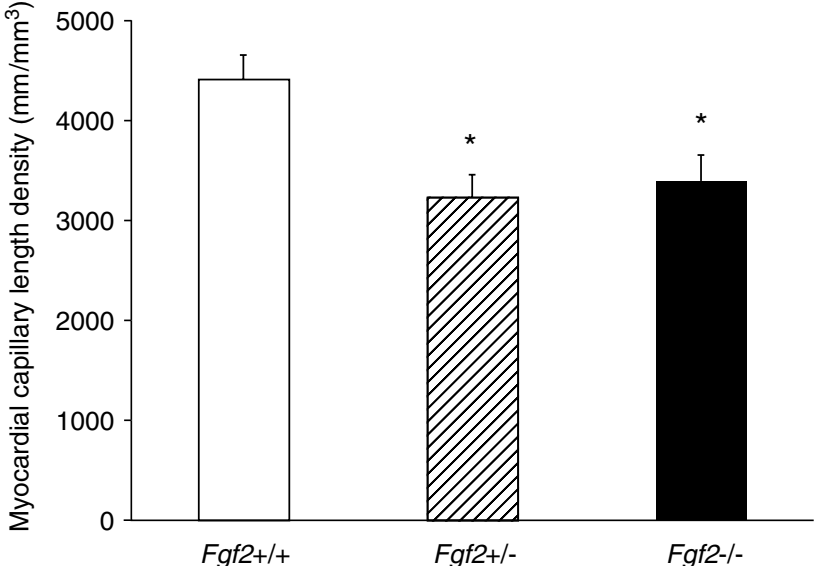

Figure 2 Statistical comparison of capillary length densities as an index of myocardial capillary supply in untreated animals (mean \pm s.e.m.). Capillary length density is significantly lower in $F g f 2^{+/-}$and $F g f 2^{-/-}$than in wild-type mice. ${ }^{*}: P<0.05$.

wild-type, $2051 \pm 109$ in $\mathrm{Fgf2} 2^{+/-}$, and $2159 \pm 545$ in $F g f 2^{-/-}$mice, respectively.

In summary, these data document that two Fgf2 genes are essential for normal postnatal capillary supply and physiological capillary growth and that loss of one or both alleles results in a substantial reduction $(-25 \%)$ of myocardial capillary length density as a parameter of three-dimensional capillary distribution in adult mice.

\section{Response to Continuous ANG II Infusion}

In order to investigate, whether capillary adaptation to myocardial hypertrophy is altered in $\mathrm{Fgf2}^{+/-}$or Fgf2 ${ }^{-/-}$mice compared to wild-type animals, ANG II was infused for 6 days.

As expected ANG II infusion led to a significant $(P<0.05)$ increase in mean arterial blood pressure (Table 2), heart weight (data not shown) and relative left ventricular weight, that is, left ventricular weight/body weight ratio (Table 2) in all ANG IItreated groups compared to untreated animals of the same genotype (for comparison see Table 1).

Figure 4 illustrates the increase in relative left ventricular weight after ANG II infusion for each experimental group compared to the untreated animals of the same genotype. Cardiac hypertrophy was also documented at the cellular level by a significant $(P<0.05)$ increase in mean myocyte diameter in all three groups after ANG II treatment (Table 2) compared to untreated animals of the same genotype.

In parallel, marked expansion of nonvascular interstitial tissue (approximately $+100 \%$ compared to baseline) developed in all groups indicating that FGF2 is not necessary for interstitial myocardial activation and expansion, respectively (Table 2). Figure $5 \mathrm{a}-\mathrm{c}$ illustrate focal activation of cardiac fibroblasts and a mild increase in interstitial fibrous tissue in wild-type, $\mathrm{Fgf2}^{+/-}$and $\mathrm{Fgf}^{-/-}$mice after ANG II infusion (compared to untreated animals of the same genotype in Figure 1a-c). The results of a
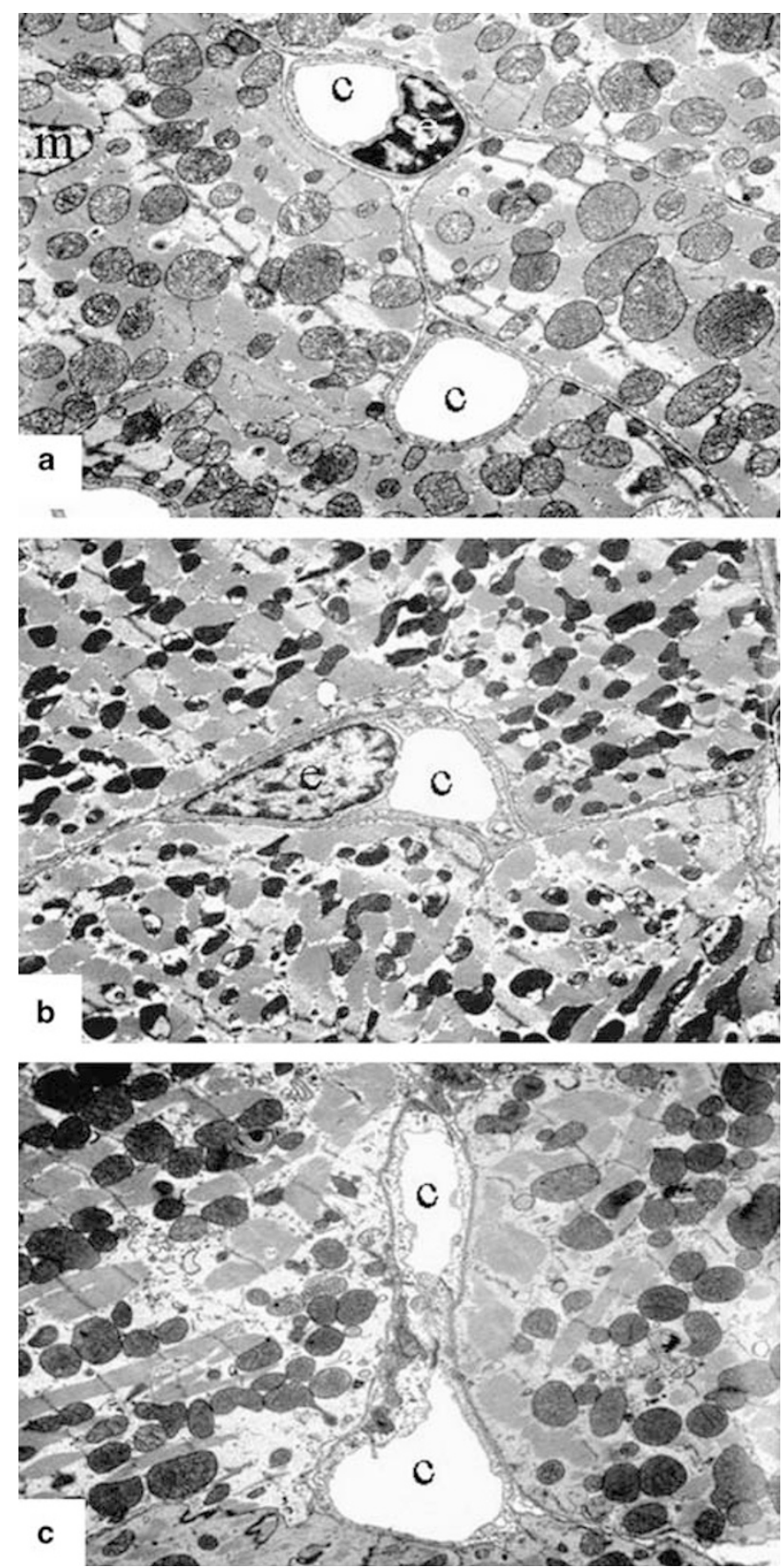

Figure 3 Ultrastructure of the myocardium in wild-type (a), $\mathrm{Fgf2}^{+/-}$(b), and Fgf2 ${ }^{-/-}$(c) mice. There are no structural alterations of cardiomyocytes (m) or capillaries (c) in Fgf2 $2^{+-}$(b) and $\mathrm{Fgf2}^{-/-}$(c) compared to wild type (a). Magnification: 1:6.000.

quantitative analysis of volume density of cardiac interstitial tissue are depicted in Figure 6. After ANG II infusion the percentage of interstitial tissue was significantly $(P<0.05)$ higher in all groups compared to untreated animals.

Wall thickness and wall to lumen ratio of intramyocardial arteries were similar in all experimental groups irrespective of ANG II treatment (Table 2). In contrast, the length density of cardiac capillaries was significantly lower in ANG II-treated wild type $\left(3521 \pm 290 \mathrm{~mm} / \mathrm{mm}^{3}\right)$ than in untreated 


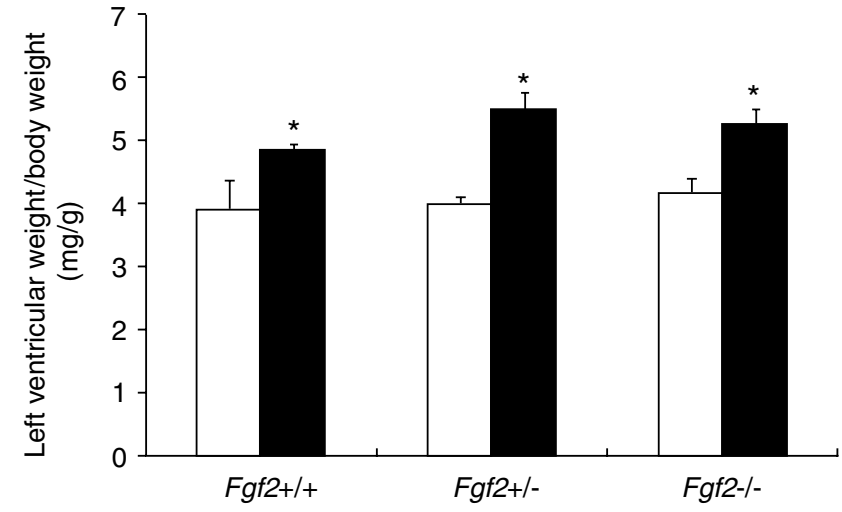

Figure 4 Myocardial hypertrophy in response to continuous ANG II infusion. Left ventricular weight/body weight ratio $(\mathrm{mg} / \mathrm{g}$, mean \pm s.e.m.). ANG II induced a significant increase in relative left ventricular weight in all three experimental groups compared to untreated animals of the same genotype. Open bars: no ANG II infusion; black bars: with ANG II infusion, ${ }^{*}: P<0.05$.

wild-type mice $\left(4403 \pm 290 \mathrm{~mm} / \mathrm{mm}^{3}, P<0.05\right)$. In contrast, in $\mathrm{Fgf2}^{+/-}$and $\mathrm{Fgf2^{-/- }}$ mice ANG II treatment caused no further decrease in capillary length density $\left(3373 \pm 289\right.$ and $3933 \pm 232 \mathrm{~mm} / \mathrm{mm}^{3}$ in ANG II-treated mice compared to $3230 \pm 245$ and $3500 \pm 241 \mathrm{~mm} / \mathrm{mm}^{3}$ in untreated animals, respectively). Mean ICD was comparable in all three ANG II-treated groups $\left(18.9 \pm 2.21\right.$ in $\mathrm{Fgf2}^{+/+}$mice, $18.9 \pm 3.25$ in $\mathrm{Fgf2}^{+/-}$mice and $17.4 \pm 1.77$ in $\mathrm{Fgf2^{-/ }}$ mice). Figure 7 shows that the total length of capillaries per heart ( $\left.L_{\text {captot }}\right)$ was significantly increased in ANG II-infused $\mathrm{Fgf2}^{+/-}$and $\mathrm{Fgf2^{-/ }}$ mice compared to untreated animals.

In summary, these findings demonstrate marked capillary growth in FGF2-deficient mice in response to ANG II-induced myocardial hypertrophy.

\section{Discussion}

The present results document that in adult mice even a loss-of-function mutation of a single Fgf2 gene leads to a substantial myocardial capillary deficit $(-25 \%)$. Since myocardial capillarization was normal at birth in FGF2-deficient mice, this finding indicates that high levels of FGF2 are required for a normal postnatal development of cardiac capillaries. The capillary deficit appears to be specific for the heart since capillary supply of other organs, for example, the kidney (data not shown), was not impaired. Moreover, the deficit appears to be strictly limited to capillaries since we did not detect any reduction of myocardial arterioles.

FGF2 serum levels are reduced to $50 \%$ in $\mathrm{Fgf2}^{+/-}$ and to zero in $\mathrm{Fgf2}^{-/-}$mice. ${ }^{5}$ Although a quantitative relation between FGF2 serum levels and myocardial capillary supply has not yet been demonstrated directly, the present findings strongly suggest that during postnatal cardiac development high levels of FGF2 are required for a normal myocardial capillarization. Interestingly, a haploinsufficiency has also been found for loss-of-function mutations of the
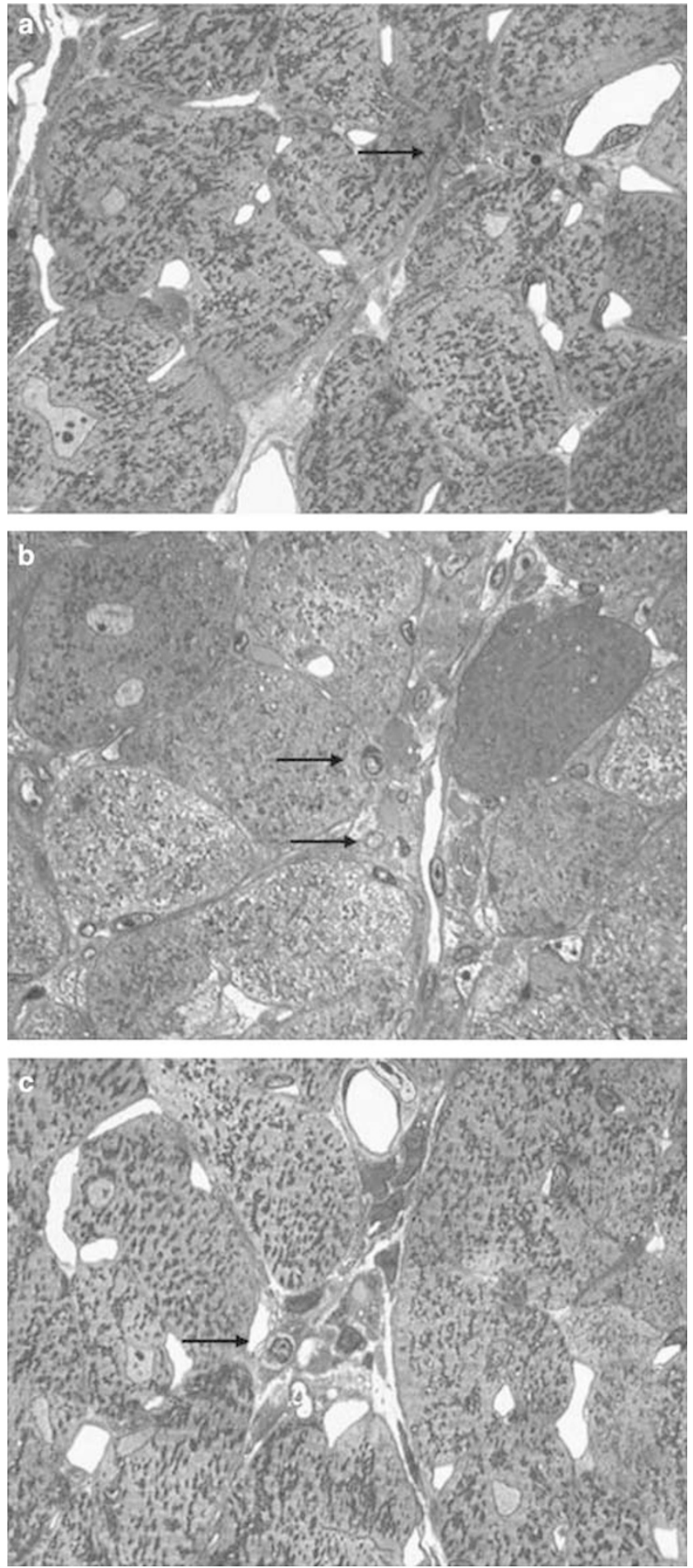

Figure 5 Effect of continuous ANG II infusion on cardiac nonvascular interstitial tissue. (a-c) Light microscopical aspect of the myocardium after ANG II infusion. An increase in cardiac interstitial tissue (ie fibroblasts indicated by arrows and interstitial fibers) was seen in wild-type (a), Fgf2 $2^{+/-}$(b), and $F g f 2^{-/-}$(c) mice after continuous ANG II infusion compared to the normal morphology in untreated animals (see Figure 1). Magnification: $1: 800$.

gene encoding interleukin-2 (IL-2) ${ }^{34}$ which maps physically to a closely related site of Fgf2 on chromosome 4 (q25-27, see Dono et $a l^{5}$ ). 


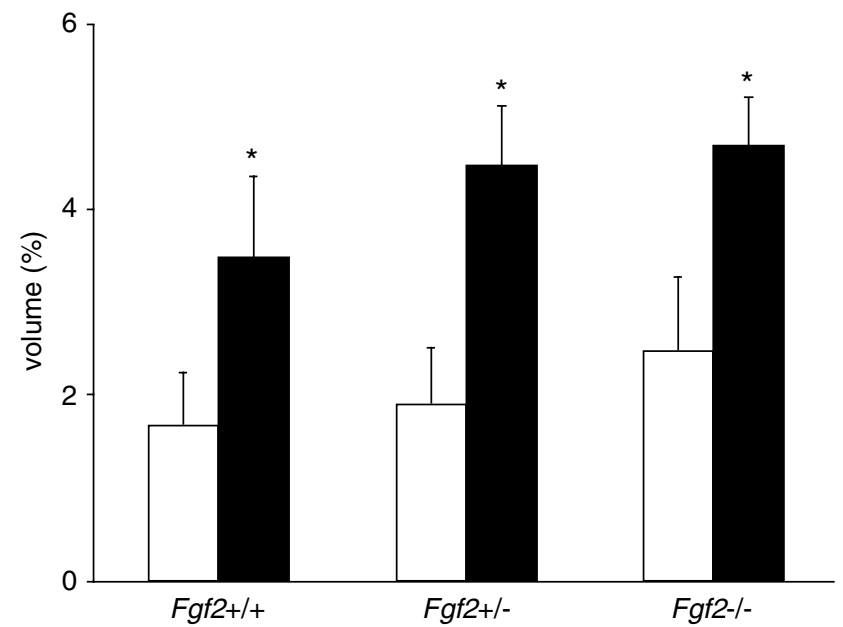

Figure 6 Statistical comparison of volume density of myocardial nonvascular interstitial tissue as an index of myocardial fibrosis after continuous ANG II infusion (mean \pm s.e.m.). The volume percentage of interstitial tissue was significantly higher after continuous ANG II infusion in all groups compared to untreated animals of the same genotype $(P<0.05)$. Open bars: untreated animals, filled: continuous ANG II infusion, ${ }^{*}: P<0.05$.

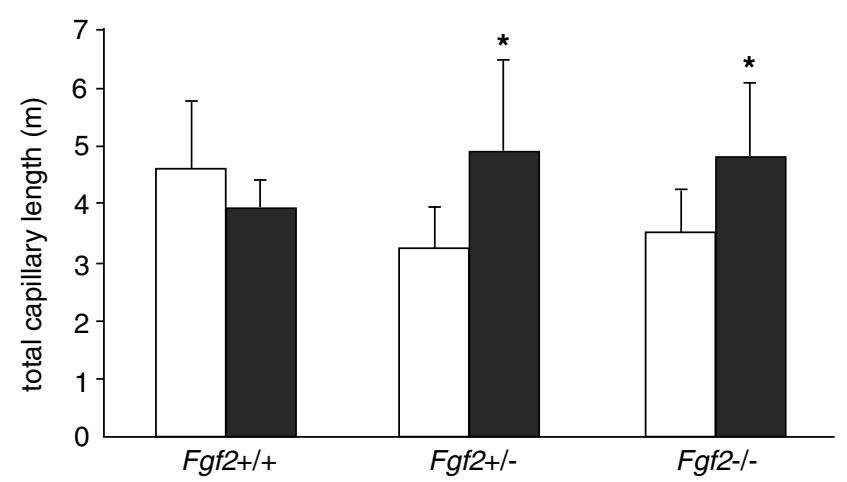

Figure 7 Capillary adaptation in response to continuous ANG II infusion. Total capillary length (m, mean \pm s.e.m.). Total capillary length after continuous ANG II infusion was significantly higher in $\mathrm{Fgf2}^{+/-}$and $\mathrm{Fgf}^{-/-}$compared to untreated animals of the same genotype. Open bars: untreated animals, filled: continuous ANG II infusion, ${ }^{*}: P<0.05$.

FGF2 expression is markedly enhanced during the early period of fetal coronary vascularization and during the early neonatal period when capillary proliferation is particularly high. ${ }^{4,35}$ In the mouse, heart transition to the adult stage is associated with a decrease of FGF2 receptor 1 mRNA expression. ${ }^{36}$ In parallel, cardiac growth is regulated by receptorcoupled FGF signaling only during tubular stages of cardiogenesis and becomes FGF independent after the second week of embryogenesis. ${ }^{37}$ Thus, FGF2 signaling appears to be particularly activated during early stages of myocardial capillarization. In contrast, FGF2 has only a minor influence on existing vessels as documented in dogs with chronic singlevessel coronary occlusion where administration of FGF2 did not have any effect on mature collateral vessels. ${ }^{38}$ Similarly, in Fgf2 $2^{-1-}$ mice with targeted disruption of the Fgf2 gene vascular growth in the mouse ischemic hindlimb was not different from wild-type mice indicating that endogenous FGF2 is not required for revascularization in the setting of peripheral ischemia. ${ }^{39}$ Using neutralizing antibodies to VEGF and FGF2 and comparable stereological techniques in perfusion-fixed rat hearts different roles of VEGF and FGF2 in early postnatal coronary angiogenesis were confirmed. ${ }^{40}$

A reduction of capillary length density has been found in several experimental models of cardiac hypertrophy. ${ }^{41}$ It is particularly pronounced in left ventricular hypertrophy due to renal insufficiency and can be documented in experimental renal failure in rats ${ }^{31,42}$ as well as in uremic patients. ${ }^{43} \mathrm{~A}$ reduction of myocardial capillary length density and intercapillary diffusion distance by $\sim 25 \%$, as found for $\mathrm{Fgf2}^{+/-}$and $\mathrm{Fgf2} 2^{-/-}$mice in the present study, does not appear to alter heart function in resting rats with subtotal nephrectomy per se because of the physiological coronary reserve (unpublished observation). A normal cardiac oxygen supply at rest would also be consistent with the absence of an expansion of myocardial interstitial tissue or myocardial fibrosis in $\mathrm{Fgf2}^{+/-}$and $\mathrm{Fgf2} 2^{-/-}$ mice (Figure 1), which are histopathological signs of chronic myocardial ischemia. In view of this finding, it is also very unlikely that the capillary changes observed in $\mathrm{Fgf2}^{+/-}$and $\mathrm{Fgf2}^{-/-}$mice are due to a possible effect of FGF2 on interstitial tissue. In addition, normal cardiac contractility was found in Fgf2 $2^{-/-}$mice. ${ }^{11}$ Cardiac oxygen supply, however, may be severely impaired if additional metabolic stress factors like an increased heart rate or cardiac hypertrophy are present. ${ }^{44}$ Such a functional ischemic cardiomyopathy has been recently described to accompany an abnormal capillarization with up to $75 \%$ reduction of capillary density in VEGF164 and VEGF188 knockout mice. ${ }^{45}$

In order to investigate the potential role of FGF2 in capillary adaptation in response to myocardial hypertrophy mice received hypertensive doses of ANG II via a continuous infusion. In all genotypes ANG II increased blood pressure and induced myocardial hypertrophy of similar degrees. In contrast to wild-type animals, total capillary length per heart increased significantly in mice deficient for FGF2 ( $\mathrm{Fgf2}^{+/-}$and $\mathrm{Fgf2} 2^{-/-}$) in response to ANG II treatment. These findings demonstrate that FGF2 is not essential for adaptive capillary growth. The mechanism(s) leading to the marked capillary growth in response to ANG II-induced myocardial hypertrophy in FGF2-deficient mice remains to be elucidated. It is of note, however, that in a recent study on the cardiac transcriptional response to acute and chronic ANG II treatment in mice Larkin et $a l^{46}$ found that the response to ANG II infusion in mice is somewhat inconsistent and in general not as marked as in rats. After acute ANG II infusions an increase in blood pressure and related changes in myocardial gene expression, but not in heart weight, was found..$^{46}$ Among the genes differently expressed 
after acute ANG II infusion were those involved in growth regulation, oxidative stress response and amino-acid metabolism.

It seems very unlikely that the physiological role of FGF2 in the adult organism would be inhibition of adaptive capillary growth. Thus, in the absence of FGF2 other growth factors may be upregulated which take over the role normally played by FGF2, thus facilitating capillary growth. In particular, major roles were shown for VEGF, angiopoietin and Tie2 in cardiac vasculogenesis and angiogenesis after ANG II infusion. ${ }^{47}$ In dogs and pigs VEGF infusion stimulated collateral vessel development in the ischemic myocardium resulting in improved cardiac global and regional function. ${ }^{48,49}$ It is also well known that the various FGF family members can substitute for each other in their respective functions. ${ }^{13}$ Thus, it seems possible that in the $\mathrm{Fgf2}^{-/-}$mouse some functions of FGF2 are taken over by other family members. This notion is supported by the observation that the FGF-receptor-deficient mouse has a distinct cardiac phenotype. ${ }^{37}$

The present finding of a preserved adaptive myocardial growth in $\mathrm{Fgf2^{-/ }}$ mice seems to be in contrast to the observation that cardiac hypertrophy induced by transverse aortic coarctation was severely

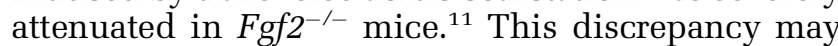
be explained by the fact that ANG II infusion and transverse aortic coarctation induce cardiac hypertrophy by activation of different intracellular-signaling cascades, ${ }^{46,50}$ partly because pressure overload by thoracic aortic coarctation does not activate the circulating renin-angiotensin system. ${ }^{51}$

The present study indicates that two intact alleles of Fgf2 are required for a normal postnatal cardiac vascularization on the capillary level, but does not appear to be essential for adaptive myocardial capillary growth in the adult mouse. FGF2-deficient adult mice represent a genetic animal model with a specific reduction of myocardial capillaries that may be very useful in cardiovascular research, for example, for the investigation of adaptive and reparative processes in chronic myocardial ischemia or myocardial infarction.

\section{Acknowledgements}

The skillful technical assistance of $\mathrm{R}$ Dussel, $\mathrm{Z}$ Antoni, P Rieger, and $\mathrm{H}$ Ziebart is gratefully acknowledged. V Balajew (Department of Pathology, University of Moscow) was recipient of a training grant of the Department of Pathology, Heidelberg. Parts of the study were supported by grants from the Thyssen Stiftung (to HE) and the IZKF Erlangen (A11).

\section{References}

1 Cordon-Cardo C, Vlodavsky I, Haimovitz-Friedman A, et al. Expression of basic fibroblast growth factor in normal human tissues. Lab Invest 1990;63:832-840.
2 Gospodarowicz D, Neufeld G, Schweigerer L. Molecular and biological characterization of fibroblast growth factor, an angiogenic factor which also controls the proliferation and differentiation of mesoderm and neuroectoderm derived cells. Cell Differ 1986;19: $1-17$.

3 Akimoto T, Hammerman MR. Fibroblast growth factor 2 promotes microvessel formation from mouse embryonic aorta. Am J Physiol Cell Physiol 2003;284: C371-C377.

4 Yokoyama M, Hirase T. Harmonic interplay of angiogenic growth factors in the development of coronary blood vessels. Circ Res 2001;88:1099-1101.

5 Dono R, Texido G, Dussel R, et al. Impaired cerebral cortex development and blood pressure regulation in FGF-2-deficient mice. EMBO J 1998;17:4213-4225.

6 Dono R, Faulhaber J, Galli A, et al. FGF2 signaling is required for the development of neuronal circuits regulating blood pressure. Circ Res 2002;90:E5-E10.

7 Zhou M, Sutliff RL, Paul RJ, et al. Fibroblast growth factor 2 control of vascular tone. Nat Med 1998;4: 201-207.

8 Dono R. Fibroblast growth factors as regulators of central nervous system development and function. Am J Physiol Regul Integr Comp Physiol 2003;284: R867-R881.

9 Ortega S, Ittmann M, Tsang SH, et al. Neuronal defects and delayed wound healing in mice lacking fibroblast growth factor 2. Proc Natl Acad Sci USA 1998;95: 5672-5677.

10 Montero A, Okada Y, Tomita M, et al. Disruption of the fibroblast growth factor-2 gene results in decreased bone mass and bone formation. J Clin Invest 2000;105: 1085-1093.

11 Schultz JE, Witt SA, Nieman ML, et al. Fibroblast growth factor-2 mediates pressure-induced hypertrophic response. J Clin Invest 1999;104:709-719.

12 Goto F, Goto K, Weindel K, et al. Synergistic effects of vascular endothelial growth factor and basic fibroblast growth factor on the proliferation and cord formation of bovine capillary endothelial cells within collagen gels. Lab Invest 1993;69:508-517.

13 Slavin J. Fibroblast growth factors: at the heart of angiogenesis. Cell Biol Int 1995;19:431-444.

14 Battler A, Scheinowitz M, Bor A, et al. Intracoronary injection of basic fibroblast growth factor enhances angiogenesis in infarcted swine myocardium. J Am Coll Cardiol 1993;22:2001-2006.

15 Lazarous DF, Shou M, Scheinowitz M, et al. Comparative effects of basic fibroblast growth factor and vascular endothelial growth factor on coronary collateral development and the arterial response to injury. Circulation 1996;94:1074-1082.

16 Lazarous DF, Scheinowitz M, Shou M, et al. Effects of chronic systemic administration of basic fibroblast growth factor on collateral development in the canine heart. Circulation 1995;91:145-153.

17 Ware JA, Simons M. Angiogenesis in ischemic heart disease. Nat Med 1997;3:158-164.

18 Yanagisawa-Miwa A, Uchida Y, Nakamura F, et al. Salvage of infarcted myocardium by angiogenic action of basic fibroblast growth factor. Science 1992;257: 1401-1403.

19 Davis MG, Zhou M, Ali S, et al. Intracrine and autocrine effects of basic fibroblast growth factor in vascular smooth muscle cells. J Mol Cell Cardiol 1997;29:1061-1072. 
20 Schweigerer L, Neufeld G, Friedman J, et al. Capillary endothelial cells express basic fibroblast growth factor, a mitogen that promotes their own growth. Nature 1987;325:257-259.

21 Kardami E, Fandrich RR. Basic fibroblast growth factor in atria and ventricles of the vertebrate heart. J Cell Biol 1989;109:1865-1875.

22 Casscells W, Speir E, Sasse J, et al. Isolation, characterization, and localization of heparin-binding growth factors in the heart. J Clin Invest 1990;85:433-441.

23 Speir E, Tanner V, Gonzalez AM, et al. Acidic and basic fibroblast growth factors in adult rat heart myocytes. Localization, regulation in culture, and effects on DNA synthesis. Circ Res 1992;71:251-259.

24 Clarke MS, Caldwell RW, Chiao H, et al. Contractioninduced cell wounding and release of fibroblast growth factor in heart. Circ Res 1995;76:927-934.

25 Pasumarthi KB, Kardami E, Cattini PA. High and low molecular weight fibroblast growth factor-2 increase proliferation of neonatal rat cardiac myocytes but have differential effects on binucleation and nuclear morphology. Evidence for both paracrine and intracrine actions of fibroblast growth factor-2. Circ Res 1996;78: 126-136.

26 Carmeliet P, Ferreira V, Breier G, et al. Abnormal blood vessel development and lethality in embryos lacking a single VEGF allele. Nature 1996;380:435-439.

27 Carmeliet P, Lampugnani MG, Moons L, et al. Targeted deficiency or cytosolic truncation of the VE-cadherin gene in mice impairs VEGF-mediated endothelial survival and angiogenesis. Cell 1999;98:147-157.

28 Cleaver O, Melton DA. Endothelial signaling during development. Nat Med 2003;9:661-668.

29 Gerber HP, Hillan KJ, Ryan AM, et al. VEGF is required for growth and survival in neonatal mice. Development 1999;126:1149-1159.

30 Lijnen P, Petrov V. Renin-angiotensin system, hypertrophy and gene expression in cardiac myocytes. J Mol Cell Cardiol 1999;31:949-970.

31 Törnig J, Amann K, Ritz E, et al. Arteriolar wall thickening, capillary rarefaction and interstitial fibrosis in the heart of rats with renal failure:the effects of ramipril, nifedipine and moxonidine. J Am Soc Nephrol 1996;7:667-675.

32 Mattfeldt T, Mall G, Gharehbaghi H, et al. Estimation of surface area and length with the orientator. J Microsc 1990;159:301-317.

33 Henquell L, Honig CR. Intercapillary distances and capillary reserve in right and left ventricles: significance for control of tissue po2. Microvasc Res 1976;12: $35-41$.

34 Hollander GA, Zuklys S, Morel C, et al. Monoallelic expression of the interleukin-2 locus. Science 1998; 279:2118-2121.

35 Tomanek RJ, Haung L, Suvarna PR, et al. Coronary vascularization during development in the rat and its relationship to basic fibroblast growth factor. Cardiovasc Res 1996;31 Spec No:E116-E126.

36 Jin Y, Pasumarthi KB, Bock ME, et al. Cloning and expression of fibroblast growth factor receptor-1 isoforms in the mouse heart: evidence for isoform switching during heart development. J Mol Cell Cardiol 1994;26:1449-1459.

37 Mima T, Ueno H, Fischman DA, et al. Fibroblast growth factor receptor is required for in vivo cardiac myocyte proliferation at early embryonic stages of heart development. Proc Natl Acad Sci USA 1995;92: $467-471$.

38 Shou M, Thirumurti V, Rajanayagam S, et al. Effect of basic fibroblast growth factor on myocardial angiogenesis in dogs with mature collateral vessels. J Am Coll Cardiol 1997;29:1102-1106.

39 Sullivan CJ, Doetschman T, Hoying JB. Targeted disruption of the Fgf2 gene does not affect vascular growth in the mouse ischemic hindlimb. J Appl Physiol 2002;93:2009-2017.

40 Tomanek RJ, Sandra A, Zheng W, et al. Vascular endothelial growth factor and basic fibroblast growth factor differentially modulate early postnatal coronary angiogenesis. Circ Res 2001;88:1135-1141.

41 Mall G, Zimmer G, Baden S, et al. Capillary neoformation in the rat heart-stereological studies on papillary muscles in hypertrophy and physiologic growth. Basic Res Cardiol 1990;85:531-540.

42 Amann K, Wiest G, Zimmer G, et al. Reduced capillary density in the myocardium of uremic rats-a stereological study. Kidney Int 1992;42:1079-1085.

43 Amann K, Breitbach M, Ritz E, et al. Myocyte/capillary mismatch in the heart of uremic patients. J Am Soc Nephrol 1998;9:1018-1022.

44 Amann K, Ritz E. Microvascular disease-the Cinderella of uraemic heart disease. Nephrol Dial Transplant 2000;15:1493-1503.

45 Carmeliet P, Ng YS, Nuyens D, et al. Impaired myocardial angiogenesis and ischemic cardiomyopathy in mice lacking the vascular endothelial growth factor isoforms VEGF164 and VEGF188. Nat Med 1999; 5:495-502.

46 Larkin JE, Frank BC, Gaspard RM, et al. Cardiac transcriptional response to acute and chronic angiotensin II treatments. Physiol Genomics 2004;18: 152-166.

47 Carmeliet P. Mechanisms of angiogenesis and arteriogenesis. Nat Med 2000;6:389-395.

48 Banai S, Jaklitsch MT, Shou M, et al. Angiogenicinduced enhancement of collateral blood flow to ischemic myocardium by vascular endothelial growth factor in dogs. Circulation 1994;89:21832189.

49 Pearlman JD, Hibberd MG, Chuang ML, et al. Magnetic resonance mapping demonstrates benefits of VEGFinduced myocardial angiogenesis. Nat Med 1995;1: 1085-1089.

50 Sugden PH. Signaling in myocardial hypertrophy: life after calcineurin? Circ Res 1999;84:633-646.

51 Wiesner RJ, Ehmke H, Faulhaber J, et al. Dissociation of left ventricular hypertrophy, beta-myosin heavy chain gene expression, and myosin isoform switch in rats after ascending aortic stenosis. Circulation 1997; 95:1253-1259. 